\title{
A ANTOlogia POÉtica no ANTIGo REgIME: APONTAMENTOS SOBRE OS APARATOS BIBLIOGRÁFICOS DA FÊNIX RENASCIDA
}

\section{Cássio Borges ${ }^{*}$ \\ DELL/UESB \\ cassiorobertoborges@hotmail.com}

RESUMO: A Fênix Renascida, antologia poética organizada por Mathias Pereira da Sylva durante a primeira metade do século XVIII, reúne a mais ampla amostra impressa da poesia seiscentista lusitana. Os cinco volumes que a integram foram editados pela primeira vez em 1716, 1717, 1718, $1721 \mathrm{e}$ 1728 , respectivamente, e, em 1746, uma vez mais "acrescentada", ela aparece em sua derradeira configuração. No presente ensaio, examinamos alguns dos aparatos bibliográficos que acompanham as impressões setecentistas dessa antologia, tendo em vista o estudo das convenções bibliográficas e dos protocolos de escrita e de leitura que balizam a sua produção e a sua circulação.

Palavras-chave: Antologia. Sociedade de Corte. Historiografia.

ABSTRACT: The Fênix Renascida, poetic anthology organized by Mathias Pereira da Sylva during the first half of the eighteenth century, gathers the broadest printed sample of Lusitanian poetry in 1600s. The five volumes belonging to Fênix Renascida were firstly edited in 1716, 1717, 1718, 1721 and 1728 respectively, and in 1746, once again, it appears in their ultimate configuration "added". In this essay, we examine some of the bibliographic apparatus that follow the 1700s prints of this anthology, in view of the survey of the conventions and protocols of writing and reading that support their production and circulation.

Keywords: Anthology. Court Society. Historiography.

* Professor Adjunto do DELL/UESB (Departamento de Estudos Linguísticos e Literários da Universidade Estadual do Sudoeste da Bahia); membro do PPGCEL (Programa de Pós-Graduação em Letras: Cultura, Educação e Linguagens). 


\section{Preliminares}

Em linhas gerais, os estudos sobre a antologia poética têm focalizado, atualmente, as relações entre esse tipo de publicação e a formação do cânon ${ }^{7}$, levantando questões a propósito das tensões que afetam o cenário literário, crítico ou didático. Essa discussão, centrada nas articulações entre as "instâncias de poder" e os dispositivos de produção, de circulação e de uso do texto poético, tem sido profusa na abordagem das práticas editoriais modernas. Contudo, são ainda escassos os estudos sobre os mecanismos editoriais que balizaram a produção de antologias antigas. No presente ensaio, propomos o exame de alguns dos aparatos bibliográficos apensos às edições setecentistas da Fênix Renascida a fim de descrever a especificidade dos critérios que presidiram a recolha efetuada por Mathias Pereira da Sylva durante a primeira metade do século XVIII.

Em estudo sobre as antologias espanholas do século XX, Ruiz Casanova (2009, p. 120) distingue, grosso modo, dois tipos de livro: as seleções "panorâmicas" e as seleções "programáticas", descrevendo estas como coleções que são elaboradas em função de "irrupções" contra o cânon e que manifestam tensionamentos no cenário crítico ou historiográfico, e aquelas como coleções de textos essenciais, com fins didáticos, que, possuindo um caráter diacrônico, comportam, em seu máximo grau, o "componente de representatividade" que deveria caracterizar "toda antologia".

7 "Con la pertinacia propia de las verdades que, a fuerza de repetidas, sobre todo en el ámbito de las Humanidades, adquieren estatus de ley indiscutible, se ha insistido en la ecuación, y relación simétrica, entre las antologías (y las historias de la literatura) y el canon literario." (RUIZ CASANOVA, 2009, p. 118)

Revista Texto Poético | ISSN: 1808-5385 | Vol. 20 (10 sem-2016) - p. 39 
Depois dessa distinção preliminar, o pesquisador da Universidade de Barcelona concentra-se nas relações entre os empreendimentos panorâmicos e os processos institucionais de formação de leitores.

Silva (2008, p. 37), por sua vez, num estudo sobre as antologias brasileiras do século XX, atém-se, inicialmente, aos tipos de antologia, distinguindo, basicamente, três espécies: as que se prestam à formação de uma "memória literária", vinculando-as aos primórdios da formação dos cânones literários nacionais; as que empreendem a "consagração" de um grupo de produtores, cobrindo uma "determinada cena literária em um espaço de tempo entre sua ebulição e a sua assimilação"; e, por fim, um terceiro tipo, mais recente, que funcionaria como um "meio - econômico para as editoras - de divulgar novas promessas." (Silva, 2008, p. 37). Ao considerar as reapropriações do "modernismo de 22" efetuadas pela "geração marginal", Silva concentra-se nos impactos dos empreendimentos "programáticos" no cenário cultural dos anos sessenta, opondo a informalidade da poesia marginal e de seus meios de circulação à formalidade do projeto concretista.

Em ambos os casos, a tônica da reflexão crítica, focada no século XX, envolve articulações entre a produção de antologias e a movência do cânon, dos paradigmas críticos e dos programas historiográficos. Em tais casos, são pertinentes questões relativas ao mercado editorial, a atuação dos agentes culturais e das instituições de ensino. A reflexão sobre as antologias antigas, entretanto, demanda o enfrentamento de pelo menos duas questões adicionais: a consideração dos regimes de historicidade em que tais obras foram produzidas e o exame das apropriações desses materiais efetuadas no bojo de outras práticas discursivas. 


\section{Antologias de antologias: tensões históricas e críticas}

De fato, como aponta Silva, nos aparatos da Fênix, prevalece o argumento a propósito da perpetuação de uma memória letrada, porém, a relação dos materiais ali recolhidos com a fixação de um cânon seiscentista lusitano é marcada por uma tensão histórica, uma vez que se trata, justamente, de um conjunto de textos que testemunha a prevalência dos modelos cultos hispânicos, herança da Monarquia Dual. Nesse sentido, a Fênix, concebida a princípio como um dispositivo de fixação de memória, também poderia ser descrita como um empreendimento "programático", empreendimento que tensiona os limites do cânon lusitano. Essa particularidade da coleção teve consequências decisivas na circulação posterior do material recolhido por Mathias Pereira da Sylva, material que, de acordo com Spina, no prefácio da Apresentação da poesia barroca portuguesa, "sempre" permaneceu relegado "a um plano despiciendo":

Vítima de preconceitos éticos, e-o que é pior - vítima de prejuizos patrióticos por se ver neles um repositório do espirito castelhano, numa época de profundo abatimento moral e de subversão das virtudes nacionais, a obra dos poetas seiscentistas sempre esteve relegada a um plano despiciendo, esperando pelo juizo do tempo, pela paciencia dos estudiosos e pela mudança dos critérios estéticos. (SPINA; SANTILLI, 1967, p. 5-6)

Esse menosprezo histórico em relação à poesia seiscentista portuguesa aparece, nesse texto de Spina, como principal obstáculo para a realização de um projeto, jamais levado a termo, de reedição integral da Fênix. A recusa sistemática dos editores justifica, nesse sentido, o abandono "provisório" do projeto inicial e a opção por publicar a obra parcialmente, sob a forma de uma antologia: 
Mas, diante do óbice criado pela sistemática recusa dos editores a uma publicação completa do Cancioneiro (por motivos evidentes) e da oportunidade também rara de publicarmos parcialmente a obra sob a forma de antologia, não tivemos dúvida de sacrificar provisoriamente o nosso objetivo inicial - há vários anos aguardando o ensejo editorial. E esta rara oportunidade, louvável por todos os títulos, devemo-la à elevada compreensão do nosso querido colega Dr. Julio Garcia Morejón, Diretor da Faculdade de Letras de Assis, a quem formulamos os nossos sinceros agradecimentos. (SPINA; SANTILLI; 1967, p.8)

Temos, portanto, duas questões: a primeira delas, de ordem historiográfica, coloca em evidência a relevância de critérios estéticos e de recortes nacionalistas na seleção do material histórico; a segunda, de ordem econômica, aponta para a inviabilidade de um projeto editorial dessa proporção, ao menos no domínio dos estudos literários luso-brasileiros. A publicação, em 2002, de uma nova antologia derivada da Fênix e do Postilhão de Apolo, Poesia seiscentista, organizada por Alcir Pécora e prefaciada por João Adolfo Hansen, atesta que o recorte nacionalista continuava, naquele momento, a suscitar tensões no debate crítico. $\mathrm{Na}$ apresentação do volume, Pécora descreve os critérios empregados na seleção dos textos. Seleção que, segundo o próprio autor, envolve escolhas "irreversivelmente parciais, artificiosas e intervencionistas" (PÉCORA, 2002, p. 16). Ali, ele explicita as razões que o levaram a incluir em sua antologia peças redigidas em espanhol:

Em seguida, ainda com sentido amostral, para afastar deste volume o ranço nacionalista que restringiu demasiado o estudo das antologias seiscentistas e de seus principais poetas, colhi vários poemas em espanhol, que era língua praticada e dominada por todo poeta de arte provada na Corte, por essa altura, verdadeiramente 
bilíngue, em parte devido à duração da Monarquia Dual, em parte pelo prestígio irresistivel dos modelos poéticos da Espanha do siglo de oro. (PÉCORA, 2002, p. 15-16)

Se o "ranço nacionalista" continuava a produzir fricção no cenário crítico, os "critérios estéticos", contudo, mudariam rapidamente. Nesse mesmo texto, Pécora descreve a "euforia do barroco" que havia tomado conta da cena intelectual durante os anos noventa, o que leva o editor a evitar a inclusão desse termo no título de sua antologia:

[...] neste início de século XXI que, bem ao contrário, vive quase uma euforia do barroco, partilhada por póscolonialistas internacionalistas (como linguagem sem doutrina, capaz de sustentar as diferenças culturais de um mundo globalizado), nacionalistas (enquanto produtos, mais ou menos acabados, capazes de encontrar um lugar particular no processo de autonomização da poesia brasileira), regionalistas (enquanto signo da riqueza do passado baiano-mineiro) etc. Tal euforia - e apenas para não usufruir dela, não se usou a palavra "barroco" no título desta seleção - ocorre a despeito do conhecimento ou, enfim, da leitura da poesia produzida no período. (PÉCORA, 2002, p. 13)

Essa mudança nos "critérios estéticos", salvo exceções, não resultou, contudo, em estudos sistemáticos da poesia seiscentista portuguesa, de tal forma que um projeto como o concebido por Spina, nos anos sessenta, ainda permanece, entre nós, como algo irrealizável. Entre os espanhóis, contudo, proliferam-se os estudos sobre a poesia seiscentista, e as antologias do séc. XVII têm sido primorosamente editadas nos últimos anos. Para referir apenas um exemplo, vale lembrar a edição da Primera parte de flores de poetas ilustres de España, que saiu em 2006, pela Cátedra. Não deixa de ser curioso observar que Mathias Pereira da Sylva, no aviso "ao 
leitor" do primeiro volume da Fênix, afirma que o exemplo dos editores espanhóis esteve entre as razões que o levaram a empreender o projeto da Fênix:

Também me persuadiram a esta empresa os exemplos de tantos quantos com escrupulosa miudeza se empenharam em descobrir e divulgar obras de alguns varões singulares para que, por meio de estampa, imortalizassem as memórias de tão grandes entendimentos. A semelhante zelo se devem os textos de Góngora, de Quevedo, de Salazar, de Polo, de Garcilaso, de Lope e outros muitos. (SYLVA. 1746; T. I; $s / p$ )

Nesse caso, como vimos, a equação entre a produção das antologias e a movência do cânon envolve, por um lado, a particularidade histórica do material compilado: a poesia produzida em Portugal durante a União Ibérica como emulação dos modelos castelhanos do siglo de oro, por outro lado, envolve as conviç̧ões críticas que se manifestam nos distintos momentos em que os textos seiscentistas foram recompilados e postos novamente em circulação. Se, como indicam os aparatos textuais da Fênix, a recolha setecentista presumia a necessidade de perenizar a memória dos "melhores engenhos portugueses", seguindo de perto os modelos editoriais castelhanos, no século $\mathrm{XX}$, quando esse material é parcialmente reeditado, os novos projetos editoriais tendem a efetuar escolhas que se empenham em promover o seu ajuste às conviç̧ões críticas e às contingências materiais que lhes são próprias, isto, até mesmo quando se pretende sanar a parcialidade de intervenções anteriores.

Nesse ponto, emerge uma segunda questão: se um projeto como o da Fênix parece-nos hoje inviável, como foi possível, no Antigo Regime, quando o processo editorial, sem dúvida, era muito mais dispendioso, realizar a impressão dos cinco volumes da 
antologia organizada por Mathias Pereira da Sylva? Nosso próximo tópico procura discutir essa questão.

\section{A Política das Letras no Antigo Regime}

Outro aspecto que parece ser relevante para a descrição das variantes históricas que afetam a produção e a circulação da antologia diz respeito às instituições políticas que envolviam a produção do livro nas oficinas da Monarquia Absolutista. A fabricação do impresso, naquele tempo, estava vinculada a um regime de "patrocínio" que permanecia à margem de questões relativas ao "mercado editorial" e que, portanto, não tinha em seu escopo a adesão de um público consumidor criticamente autônomo. Como aponta Diogo (2003), "na época da Fênix e em seiscentos" a "representação por letra de imprensa em geral fez-se conforme à representação de aparato que assimila o público e o cerimonial":

Ao invés do que acontece aos tipos de textos que virão a ser literários, na época da Fênix e em Seiscentos a tipografia é sobretudo utilizada por duas instituições com propósitos idênticos ou coadunáveis, quais são o Estado e a Igreja, que ao primeiro se encontra relativamente subordinada. A prensa é um dos meios usados pelos aparelhos com monopólio tendencial da representação e dos seus sinais. (cf. HABERMAS, 1989) Na verdade, a representação por letra de imprensa em geral fez-se conforme à representação de aparato que assimila o público e o cerimonial, e de que intencionalmente se aproximaram muitos fastos de erudição (basta lembrar os dados à estampa pelas academias, as orações e as lições). (DIOGO, 2003, p. 100)

Nas letras do Antigo Regime, a convenção retórico-poética que balizava a composição dos textos presumia, simultaneamente, a 
proeminência de finalidades civis que divergiam, em grande medida, dos pressupostos estéticos que aproximam literatura e mercadoria, razão pela qual Diogo opõe os textos impressos do Antigo Regime àqueles que, mais tarde, serão tratados como textos "literários", como aponta Hansen:

Os processos da inventio e da elocutio fundamentam não uma "estética", que pressupõe a psicologia do autor, a autonomia estética e a livre-concorrência da obra no mercado como a mercadoria "originalidade" apropriada por públicos dotados de autonomia crítica, mas uma técnica, que é um saber-fazer ou uma ciência retórica dos preceitos, procedimentos técnicos e efeitos verossimeis e decorosos específicos da racionalidade não-psicológica da mímesis aristotélica reciclada neoescolasticamente. (HANSEN, 2000, p. 323).

As dedicatórias apensas a tais edições explicitam claramente essa divergência entre as nossas práticas editoriais e os usos antigos. Ao empreender a solicitação de patrocínio a uma autoridade política, o argumento desse aparato textual, operando em gênero laudatório, empenhava-se regularmente na demonstração da equivalência entre o valor do empreendimento bibliográfico realizado e a dignidade da posição hierárquica requisitada, ou seja, se, por um lado, a autoridade do "mecenas" desempenhava o papel de uma instituição política que poderia avalizar o mérito do impresso, por outro, a impressão do volume era concebida como um dispositivo bibliográfico que poderia garantir a posteridade da memória do patrocínio, concebido, naquele tempo, como um ato de "zelo" em relação ao "crédito" da pátria. Tratava-se, pois, para usar uma expressão de Norbert Elias (2001; 1994), de uma "economia de status" que concebia as práticas de representação letrada como elementos cruciais no jogo das práticas de representação política. 
$\mathrm{O}$ argumento da dedicatória do primeiro tomo da Fênix, "Ao excelentíssimo senhor D. Francisco de Portugal, Marquês de Valença, Conde de Vimioso [...]", atende perfeitamente a essa convenção. Ele levanta inicialmente uma relação de semelhança (melhor/melhores) entre a excelência do "mecenas" e a dos "engenhos" recolhidos pela antologia: "As obras dos melhores engenhos portugueses dedico hoje, com venturoso acerto, ao melhor Portugal [...] (SYLVA. 1746; T. I; s/p). Note-se que a passagem em questão explora a ambiguidade do nome do Marquês, dando margem a duas leituras: uma, mais genérica, refere-se a toda a linhagem dos Condes de Vimioso, designando, portanto, a nobreza dessa "casa"; a outra, mais específica, designa a pessoa de D. Francisco relativamente aos seus ancestrais, ou seja, assevera-se que ele não apenas tenha honrado o nome de seus antepassados, equiparando-se a eles, mas que também os tenha superado. Trata-se de um lugar comum da retórica laudatória, ${ }^{8}$ o que, nesse caso, funciona como uma insinuação preliminar da hipótese que será exposta ao longo da peça.

Como consequência da asseveração anterior, a excelência do mecenas, a dedicatória aventa a possibilidade de que se recupere, sob a proteção de um "português tão zeloso", a estima daqueles que, merecendo "os maiores aplausos da fama", permanecem, contudo, "sepultados no esquecimento". Esse é um ponto nuclear do argumento de Mathias Pereira da Sylva: salvar do esquecimento os frutos da melhor "discrição" portuguesa. O impresso é, pois, tratado como um dispositivo de perpetuação de memória e seu patrocínio como uma ação que, ao manifestar o "zelo" em relação às

${ }^{8}$ A mesma tópica laudatória é utilizada, por exemplo, num soneto de Camões que efetua o encômio da casa dos Meneses: "Ilustre e digno ramo dos Meneses".

Revista Texto Poético | ISSN: 1808-5385 | Vol. 20 (10 sem-2016) - p. 47 
instituições letradas, zela consequentemente pela perpetuação das instituições políticas.

O desdobramento da proposição levantada mobiliza, logo em seguida, algumas variações sobre tópica da raridade, concentrando-se na exploração dos signos de distinção que poderiam demonstrar a grandeza do Conde. Depois de constatar a predileção dos portugueses por obras estrangeiras, em detrimento das próprias, a descrição desse "estranhável desprimor" focaliza, por um lado, a categoria da quantidade, por outro, a do tempo, constatando seu alcance "quase" universal, assim como sua longa duração. De fato, trata-se de um tema recorrente que, desde o século XVI, vinha sendo mobilizado pelos discursos em louvor ou em defesa do vernáculo, como se lê, por exemplo, nos Diálogos de João de Barros e de Pero de Magalhães de Gandavo (HUE, 2007). ${ }^{9}$

Em tais discussões, a admiração dos modelos poéticos hispânicos ou toscanos é usualmente apontada como causa do descaso em relação a própria língua, de tal forma que, nesse ponto, a dedicatória de Mathias Pereira da Sylva converge com um antigo debate que considerava a fixação de usos "nobres" do vernáculo condição para a conservação e para a expansão do "corpo místico" do Reino. Nesse sentido, a política letrada da monarquia absolutista arquitetava-se, basicamente, por meio de duas frentes de trabalho: de um lado, por meio da elaboração das artes de escrever, sejam elas de gramática, de retórica ou de poética; de outro, por meio da compilação de modelos de excelência que pudessem orientar os usos da língua vulgar. Essa demanda é frequentemente referida como a principal motivação para a reunião e a impressão de obras poéticas produzidas na Península Ibérica durante os séculos XVI e XVII. As

9 Ver a edição de Hue. "Diálogo em louvor da nossa linguagem" (1540), de João de Barros; "Diálogo em defesa da língua portuguesa" (1574), de Pero de Magalhães de Gandavo.

Revista Texto Poético | ISSN: 1808-5385 | Vol. 20 (10 sem-2016) - p. 48 
Anotaciones a la poesía de Garcilaso, de Fernando de Herrera (2001), são, nesse sentido, emblemáticas, pois, além de compilar e de editar os poemas, Herrera comenta profusamente cada uma das peças, elaborando o primeiro esboço de uma arte poética dedicada a uma língua ibérica. O projeto editorial da Fênix insere-se, ainda, nessa estratégia política de atualização monárquica do vernáculo, recolhendo os modelos lusitanos que haviam empreendido um tratamento "culto" da língua portuguesa, ou seja, que haviam empregado um registro elocutivo pautado pelo uso profuso de correlações analógicas "agudas", normativamente consagradas pelas "artes de engenho" durante o século XVII.

Posta a demanda relativa à necessidade perpétua de "aprimoramento" da língua, os encômios do vernáculo incluíam, regularmente, incitações aos agentes letrados capacitados para essa empresa filológica. No caso da dedicatória que estamos examinando, contudo, D. Francisco de Portugal não é incitado a acolher a Fênix a fim de favorecer esse processo, ele é caracterizado como um agente que vinha atuando, efetivamente, no cultivo da língua portuguesa, constituindo, dessa forma, a exceção à regra enunciada anteriormente:

Mas se não é novo esse pouco afeto aos nossos, por mostrar muito aos alheios, não deixa de ter essa quase universal máxima uma tão grande exceção como a Vossa Excelência, em quem lançou altíssimas raizes o crédito da pátria, que, por tantos meios, procura adiantar. (SYLVA. 1746; T. I; $s / p)$

Nesse ponto, o texto investe definitivamente no encômio do Marquês, focalizando inicialmente seu empenho em relação ao prestígio da pátria. A enumeração dos atos "heroicos" que poderiam demonstrar a "verdade" da proposição inicial é, contudo, levantada 
apenas hipoteticamente, considerando-se suficiente para demonstração em questão a afirmação da notoriedade de tais fatos, o que não apenas garantiria a sua transmissão para as futuras gerações, mas também justificaria a supressão de sua especificação. Em síntese, admite-se, por exageração, que a magnificência e a generosidade de D. Francisco de Portugal, amplamente reconhecidas por sua raridade e, portanto, por sua distinção, servirão de "protótipo" para as gerações vindouras, mesmo na ausência desse testemunho impresso.

Retomando, logo em seguida, a analogia inicial entre o Marquês e a Fênix, o argumento empenha-se, então, em atenuar a solicitação de patrocínio, afirmando que a Fênix "busca" o Marquês não por "ambição", mas por semelhança e por simpatia, de tal forma que as qualidades agora atribuídas a D. Francisco, "grandes partes" e "relevantes rendas", reduplicam-se como qualidades do livro dedicado a ele:

Mas não busca ela [a Fênix] a V. Excelência só com a ambição do patrocínio, se não levada da simpatia $e$ semelhança que se gloria ter com V. Excelência, cujas grandes partes e relevantes prendas of fazem outra Fênix da Lusitânia para maior glória dos portugueses. (SYLVA. 1746; T. I; $s / p$ )

Tendo, antes, consolidado a correlação aguda que identifica as qualidades do Marquês com as da antologia poética a ele dedicada, agora, a mesma analogia desdobra-se em uma ponderação "histórica" sobre a criatura mítica que dá nome à antologia. Aludese, então, ao texto do VI livro dos Anais de Tácito, que relata, por sua vez, aquela que teria sido a "única" aparição desse "alado milagre da natureza", no Egito, na época do consulado de Lúcio Vitélio e Paulo Fábio. Essa alusão "histórica”, ao enfatizar a raridade 
do "fato" descrito pelo "historiador político", favorece uma nova retomada da tópica da raridade, levantando outra correlação de semelhança, agora, entre os atributos da criatura mítica, única, e os atributos do Marquês, único. Se antes o "mecenas" aparecia como o "melhor Portugal", agora, no conjunto mais restrito de sua "casa", ele aparece como o "melhor Fênix". Resolve-se, dessa forma, a artificiosa ambiguidade que abria a dedicatória:

E que venturoso deve chamar-se Portugal, quando depois de tantos séculos, quantos conta a ilustríssima $e$ esclarecida casa de V. Excelencia, chegou a lograr em $V$. Excelência o melhor Fênix! (SYLVA. 1746; T. I; s/p)

Bem, se D. Francisco é Fênix, é necessário, por fim, retificar a origem do mito, ou melhor, do "relato histórico", atualizando a autoridade das fontes. O achado de Mathias Pereira da Sylva, nesse caso, deriva-se das Miscelâneas de João Esteves que, de acordo como o organizador da antologia, está entre os poucos autores que acertaram ao situar a Fênix em "um nobre lugar do ocidente inacessível aos homens". Que lugar seria esse? Feita a cama, o editor não hesita em afirmar que é Portugal:

Mas que nobre lugar do Ocidente pode ser esse, se não o nobilíssimo Portugal, cujas singulares prendas o remontam tanto que corta as esperanças de ser imitado, quando se apropria a prerrogativa de ser único? Este sim, Excelentíssimo Senhor, este é o verdadeiro lugar do Ocidente, pátria de tão singular prodígio. (SYLVA. 1746; T. I; $s / p$ )

A conclusão da dedicatória alega, por fim, que a semelhança até aqui explicitada teria sido a causa da segura eleição de D. Francisco de Portugal para o patrocínio da Fênix Renascida. Por convenção, a contrapartida do patrocínio é a promessa da perpetuação do nome da autoridade que fomenta a produção do monumento letrado. Nesse 
momento, o organizador da Fênix converte a correlação de propriedades já desenvolvida em correlação de duração: se a Fênix é única por sua raridade, se o Fênix é único por sua excelência política e se a Fênix é única por sua excelência letrada, correlação de propriedades, na duração, a Fênix é imortal por natureza, o Fênix é imortal por patrocínio e a Fênix é imortal por "indústria":

Multiplique V. Excelência, qual outra Fênix os seus dias, igualando na duração a que representa nas propriedades, para honra dos Portugueses, para ornamento de sua nobilíssima casa e para amparo de todos os que nos confessamos criados de V. Excelência. (SYLVA. 1746; T. I; s/p)

Sem maiores preocupações com a verossimilhança histórica de sua proposição, Mathias Pereira da Sylva empenha-se em produzir um louvor de D. Francisco de Portugal pautado por critérios de distinção que vinculam a atuação política ao fomento da prática letrada, concebendo a conservação antológica do texto poético como uma política de Estado, como fixação de um repertório de usos da linguagem que poderia garantir a perpetuação do "processo civilizador" (ELIAS, 1994) que impulsiona a máquina bélica da Monarquia Absolutista.

\section{Ruínas e representatividades}

Por fim, um terceiro aspecto chama a atenção no que concerne às diferenças em questão: um aspecto relativo à "representatividade". Como aponta Ruiz Casanova, a antologia "panorâmica", entre as quais ele inclui a antologia de "época", deveria operar num grau máximo de representatividade. Sem dúvida, a Fênix Renascida, juntamente com o Postilhão de Apolo, constitui uma fonte elementar para as diversas antologias que 
pretenderam colocar em circulação uma amostra representativa da poesia "barroca" portuguesa. Ao longo do tempo, contudo, essas antologias de antologias estabeleceram diferentes critérios de representatividade, adotando procedimentos de amostragem pautados por convicções alheias ao regime de historicidade que havia balizado a recolha setecentista. Um bom exemplo desse tipo de procedimento aparece na "Introdução" da já referida Apresentação da poesia barroca portuguesa, redigida por Maria Aparecida Santilli:

Para arranjar num só volume a amostra variegada e expressiva dos cinco publicados por Mathias Pereira da Sylva, de poemas predominantemente longos, cortes profundos foram necessários. Deixou-se de lado, assim, a grande massa de poemas escritos em espanhol, pois a antologia destina a ser de textos portugueses. Foram rejeitadas, quase totalmente, as composições encomiásticas, porque, embora abundantes nas duas coletâneas setecentistas, se reduzem a poesia de circunstância, com o objetivo único de exaltar - e num grau superlativo - as virtudes de pessoas, quase sempre altas personalidades da época. [...] Em face, pois, de seu pouco ou nenhum valor poético, a poesia dessa natureza seria a de menor interesse. Afora isso se eliminou, também quase totalmente, a poesia de tipo burlesco ou satírico, por caracterizar-se como satisfação puramente circunstancial do poeta, sem mais valores. (SPINA; SANTILLI; 1967, p. 62)

Em relação ao primeiro ponto mencionado por Santilli, a exclusão dos textos em espanhol, fica evidente que, nesse caso, não se considera a particularidade histórica do material antigo, fruto de uma corte bilíngue, como já discutimos, no comentário da nota introdutória de Pécora para a Poesia Seiscentista. A organizadora do volume sequer discute a questão, afirmando categoricamente que seu projeto de edição se destinava a recolher apenas textos portugueses. 
Em relação ao segundo grupo de exclusão, a dos textos encomiásticos, a autora justifica-se afirmando que tais textos teriam "pouco ou nenhum valor poético". Bem, uma vez mais, fica evidente que tais critérios de seleção não levam em consideração a convenção discursiva do Antigo Regime, nem os empregos do texto poético na Sociedade de Corte. Os poemas epidícticos estavam visceralmente atrelados às práticas sociais monárquicas, ali a poesia laudatória funcionava como um dispositivo de fabricação de distinções e de difusão de valores áulicos. Como afirma Elias:

Como a observação dos outros era uma das artes de importância mais vital para os cortesãos, é compreensivel que a arte de descrever as pessoas, nas memórias, cartas e aforismos tenha chegado a um alto grau de perfeição. (ELIAS, 2001, p. 122)

Ou seja, se a atinência ao pressuposto da autonomia estética exige que se deixe de lado toda a poesia quinhentista e seiscentista dedicada à descrição de pessoas, concebendo-a como uma poesia "sem valor", perde-se de vista uma prática de escrita que interferia diretamente na "economia de prestígio" que ordenava as relações interpessoais na corte, relações que, nesse caso, eram também relações políticas.

A mesma objeção poderia ser levantada em relação ao terceiro grupo de textos excluídos por Santilli, o dos textos burlescos ou satíricos que, concebidos como textos "sem valor", como fruto da "satisfação puramente circunstancial do poeta", são sumariamente descartados. Na preceptiva poética produzida durante o Antigo Regime, assim como nos tratados de racionalidade de corte, o uso de argumentos destinados à moção do riso foi exaustivamente codificado. Nesses textos, o emprego venial da "graça" havia sido concebido não apenas como uma habilidade decisiva para o prazer 
da conversação cortês, mas também como um dispositivo doutrinário de ordenação dos modos no interior do "corpo místico" do Reino, uma vez que, genericamente formulados, os vícios representados em argumentos cômicos poderiam explicitar os hábitos que deveriam ser evitados.

Enfim, presumimos que, na reflexão sobre a poesia dos séculos XVI e XVII, a investigação das convenções éticas, retóricas e poéticas que estiveram em vigência na ocasião da composição dos textos possa permitir uma reavaliação dos postulados que ordinariamente presidem a valoração dos diferentes gêneros de composição poética, permitindo, dessa forma, uma apreciação mais verossímil das práticas discursivas monárquicas.

Os critérios modernos de representatividade sobrepõem-se, ademais, a um crivo anterior: o que havia sido colocado em prática na primeira recolha. No que diz respeito a esse ponto, os aparatos Fênix também revelam pistas importantes. No aviso "ao leitor" do primeiro volume, Mathias Pereira da Sylva dedica boa parte de seu argumento à exposição das razões que o levaram a empreender a publicação impressa de sua "singular" coleção manuscrita:

Porque entendi que defraudava a nação portuguesa de grande glória, se com ambiciosa sofreguidão retivesse os muitos e singulares manuscritos que deste gênero tenho visto e guardo em meu poder. Não me moveu a não os publicar a singularidade e regalia de ser o único nessa posse, porque esta me não dá coisa que me não dê a comunicação das mesmas obras. Nesta matéria, a avareza dá pouco lucro, e por limitado deve desprezar-se. (SYLVA. 1746; T. I; $s / p$ )

Afetando modéstia, Mathias Pereira da Sylva mobiliza inicialmente uma tópica antiga que contrapunha a partilha da riqueza e do saber, opondo, correlativamente, diminuição e aumento. A 
generosidade do colecionador configura-se, pois, como o ponto de partida para o empreendimento tipográfico da Fênix Renascida. Logo em seguida, esse aviso "ao leitor" refere-se à desordem em que se encontrava o material manuscrito depois de tanto tempo de circulação em folhas soltas e, portanto, de tantos traslados, processo que teria acarretado o acúmulo de inúmeras variantes, algumas truncadas, outras alteradas. A menção a essa circunstância, ao favorecer, no argumento do "aviso", o encarecimento do trabalho de edição, acaba fornecendo algumas pistas sobre os procedimentos de estabelecimento de texto, que, de acordo com o organizador, envolveu não apenas o cotejo das incontáveis variantes, mas também a consulta a "amigos que melhor o entendiam":

Não pouco trabalho me custou o pô-los em limpo, para o que me foi necessário ver e conferir muitos traslados, porque a grande variedade que deles se tem feito foi a causa de não andarem todos do mesmo modo, padecendo alguns de diminuição, outros misturando intoleráveis alterações. Por essa razão deve estranhar-se o irem trocadas ou acrescentadas algumas palavras, porque, nesse ponto, segui o que me pareceu mais ajustado, com conselho de amigos que melhor o entendiam. (SYLVA. 1746; T. I; $s / p$ )

Depois de explicitar a motivações que o levaram a imprimir as "obras dos melhores engenhos portugueses" e de encarecer o labor filológico exigido por tal empreitada, Mathias Pereira da Sylva tece algumas observações sobre os critérios de disposição que orientaram a organização dos volumes. Nessa passagem, o que se lê, de fato, é uma justificativa para a ordenação caótica que prevalece nos cinco volumes dessa coletânea, sobretudo, em sua última impressão aumentada. Neles, nenhum dos critérios usuais em edições do Antigo Regime, como o gênero textual a que pertencem as 
composições, a língua em que foram redigidas ou a autoridade a que elas haviam sido atribuídas, podem ser nitidamente apontados como uma diretriz proeminente. Nesse caso, o organizador refere-se apenas ao critério de autoria, alegando que não arranjou os textos dessa forma por considerar a possibilidade de inclusão, nos volumes subsequentes, de alguma nova composição que, no momento do fechamento dos tomos anteriores, ele ainda "não tivesse notícia":

Não dou juntas todas as obras de cada um autor; assim porque me pareceu mais conveniente que em todos os tomos tivessem todos parte e, deste modo multiplicados, chegasse a notícia de todos a cada um deles, como também para que se, depois de impressas juntas todas as obras de cada um, aparecesse outra, de que eu não tivesse notícia, não ficasse privada de seu lugar entre as outras; porque dificultosamente o teria particular depois de todas as outras já impressas e separadas. (SYLVA. 1746; T. I; s/p)

Nesse mesmo texto, Mathias Pereira da Sylva refere-se, ainda, a uma preocupação adicional: selecionar apenas composições "edificantes", tendo em vista o "proveito" dos potenciais leitores e a preservação dos "bons costumes", o que, desse ponto vista, implicava excluir da edição todos os papéis que, pertencendo à sua ampla coleção manuscrita, poderiam soar como "profanos" ou "impudicos", ou seja, os critérios de "representatividade" do editor setecentista haviam sido moldados a partir de convicções claramente datadas:

Não tenho tenção de dar nestes Tomos as obras que por profanas ou impudicas não o merecem. Porque o meu intento é de aproveitar a quem as ler com a erudição $e$ esquisita suavidade; e não destruir os bons costumes. Nem se me deve estranhar a resolução, que mais seria digna de um religioso, que de quem o não é, porque a modéstia também pode andar de capa e espada. Nem sei que haja 
obrigação de pôr de parte o pejo, a quem não vive dentro de claustros. (SYLVA, 1746, s/p)

Em passagens como essa, fica nítida a preocupação dos editores antigos com os aspectos éticos que poderiam estar envolvidos na difusão das diferentes modalidades de textos poéticos. Vale lembrar, nesse ponto, que os aparatos textuais das edições antigas, usualmente, testemunham a presença de mecanismos censórios aos quais os textos deveriam ser submetidos durante o processo formal de editoração: taças e licenças que atestavam a adequação dos textos aos princípios teológico-políticos que fundamentavam a instituição política.

Considerando tais fatores, é possível inferir que os materiais conservados por coletâneas antigas representam apenas uma pequena fração dos papéis que efetivamente circularam na antiga sociedade de corte, em folhas soltas, manuscritas, difundidas anônima e sub-repticiamente, ou seja, a fixação impressa aparece, nesse sentido, sob a figura de uma ruína, de uma materialidade indicial que testemunha arqueologicamente a efetividade de uma prática discursiva que jamais poderemos reconstruir. Estamos, portanto, fadados a forjar, na melhor das hipóteses, representatividades restritas, a forjar representatividades de resquícios conservados em arquivos e bibliotecas, sejam eles impressos, sejam manuscritos.

\section{Considerações Finais}

No presente ensaio, tomamos como ponto de partida algumas categorias de classificação da antologia poética que são recorrentes em estudos atuais sobre esse tipo de publicação, estudos 
regularmente centrados nas relações entre a circulação impressa do texto poético e a formação do cânon literário, ou seja, centrados na relação entre as práticas discursivas da literatura e sua relação com as instâncias de poder. Partindo, pois, da "dualidade fundamental" (RUIZ CASANOVA, 2009) entre as antologias "panorâmicas" e as antologias "programáticas", propúnhamos o exame de uma antologia antiga, a Fênix Renascida, presumindo que esse tipo de objeto demandava a consideração de dois fatores adicionais: a do regime de historicidade que vigia durante a realização do empreendimento estudado e a das reapropriações modernas de tais materiais. Na primeira parte, observamos a interferência de fatores historiográficos e de tensões críticas nos projetos antológicos de Apresentação da poesia barroca portuguesa e de Poesia Seiscentista. Na segunda parte, examinamos a "política das letras no antigo regime", discutindo as convenções textuais e editoriais que operam na dedicatória do primeiro volume da Fênix e identificando, ali, algumas particularidades que concernem às práticas editoriais do Antigo Regime em suas articulações com as instituições políticas da sociedade de corte. Por fim, examinamos os critérios de representatividade que ordenaram a seleção dos materiais coligidos tanto na primeira recolha quanto em uma das apropriações modernas da poesia seiscentista portuguesa. Considerando, pois, essa trajetória, cremos que seja possível propor que o estudo da história das antologias poderia resultar em contribuições relevantes para os atuais estudos relativos à "poética da antologia", para utilizar, uma vez mais, uma expressão de Ruiz Casanova, pois, parece-nos, foi possível constatar a variabilidade histórica dos padrões que balizam a composição, a circulação e a apropriação da antologia poética. 


\section{Referências}

DIOGO, Américo António Lindeza. Considerações sobre o Curto, a partir do Tomo I da Fénix Renascida. Estudios Portugueses. Revista de Filología Portuguesa, n. 3, 2003, p. 93-102.

ELIAS, N. A sociedade de corte: investigação sobre a sociologia da realeza e da aristocracia de corte. Tradução Pedro Süssekind. Prefácio Roger Chartier. Rio de Janeiro: Jorge Zahar Editor, 2001.

ELIAS, N. O processo civilizador: formação do estado e civilização. Tradução Ruy Jungmann. Revisão, apresentação e notas Renato Janine Ribeiro. Rio de Janeiro: Jorge Zahar Editor, 1994.

ESPINOSA, P. (org.). Primera parte de flores de poetas ilustres de Espanã. Edición de Inoria Pepe Sarno y José-María Reyes Cano. Madrid, Cátedra, 2006.

HANSEN, J. A. Retórica da Agudeza. In Letras Clássicas, n. 4, 2000, p. 317-342.

HERRERA, F. Anotaciones a la poesía de Garcilaso. Edição Inoria Pepe Sarno e José-María Reyes Cano. Madrid: Cátedra, 2001.

HUE, S. M. (org.). Diálogos em louvor da Língua Portuguesa. Rio de Janeiro: 7Letras, 2007.

PÉCORA, A. (org.). Poesia seiscentista: Fênix renascida \& Postilhão de Apolo. Introdução João Adolfo Hansen. São Paulo: Hedra, 2002.

RUIZ CASANOVA, José Francisco. Canon y Teaching Anthologies: en torno a la enseñanza de la poesía y la pervivencia de Ambas. In Revista Signa 18, 2009, p. 115-128.

SILVA, A. P. Antologia poética: a geração marginal e o modernismo de 22. In Ipotesi, v. 12, n. 2, jul./dez. 2008, p. 37-46. 
SYLVA, M. P. (org.). A fênix renascida ou obras poéticas dos melhores engenhos portugueses. Segunda vez impresso e acrescentado. Lisboa: Oficina dos Herdeiros de António Pedroso Galram, 1746.

SPINA, S.; SANTILLI, M. A. Apresentação da poesia barroca portuguesa. São Paulo: Assis, 1967. p. 9-56. 